\title{
Field Validation of IEC 61400-27-1 Wind Generation Type 3 Model with Plant Power Factor Controller
}

\author{
Göksu, Ömer; Altin, Müfit; Fortmann, Jens; Sørensen, Poul Ejnar
}

Published in:

IEEE Transactions on Energy Conversion

Link to article, DOI:

10.1109/TEC.2016.2540006

Publication date:

2016

Document Version

Peer reviewed version

Link back to DTU Orbit

Citation (APA):

Göksu, Ö., Altin, M., Fortmann, J., \& Sørensen, P. E. (2016). Field Validation of IEC 61400-27-1 Wind Generation Type 3 Model with Plant Power Factor Controller. IEEE Transactions on Energy Conversion, 31(3), 1170 - 1178. https://doi.org/10.1109/TEC.2016.2540006

\section{General rights}

Copyright and moral rights for the publications made accessible in the public portal are retained by the authors and/or other copyright owners and it is a condition of accessing publications that users recognise and abide by the legal requirements associated with these rights.

- Users may download and print one copy of any publication from the public portal for the purpose of private study or research.

- You may not further distribute the material or use it for any profit-making activity or commercial gain

- You may freely distribute the URL identifying the publication in the public portal 


\title{
Field Validation of IEC 61400-27-1 Wind Generation Type 3 Model with Plant Power Factor Controller
}

\author{
Ömer Göksu, Member, IEEE, Müfit Altin, Member, IEEE, Jens Fortmann, Member, IEEE, \\ and Poul E. Sørensen, Senior Member, IEEE
}

\begin{abstract}
Generic electrical simulation models of wind power generation have been developed as standards, such as the IEC 61400-27-1, to be used by wind industry, system operators, and academia for power system stability studies. In this paper the IEC type 3 wind turbine model with wind turbine level voltage controller and with wind power plant level power factor controller is validated based on field measurements from a 52 MW wind power plant. In addition to the validation of the IEC type 3 wind turbine and wind power plant controller models, a comparison of the validation approaches, which are the full grid and play-back simulation, is provided together with a survey of the existing validation studies and recommendations for future modeling and validation tasks. The implemented IEC models are tuned to match the measurements accurately and the validated values for the control parameters of the reference wind power plant model are given.
\end{abstract}

Index Terms - Wind turbine generators, wind farms, wind energy integration, power system simulation, reactive power control, power system modeling, IEC standards

\section{INTRODUCTION}

$\mathrm{I}^{\mathrm{N}}$ NCREASING share of wind power has created the need for wind turbine (WT) and wind power plant (WPP) models to be used in power system stability analysis. Modeling studies conducted by wind industry, academia, and power system software vendors are usually based on manufacturer specific models in order to provide sufficient accuracy. But these models are complex with many details and generally confidential. Standardization of the wind power models that are both generally available and sufficiently accurate has been accomplished in order to provide generic wind power models, which can be used by system operators of countries, wind industry, academia, and power system software vendors [1][3]. In February 2015, IEC TC88 working group 27 has published the IEC 61400-27-1 wind turbines - electrical simulation models standard [1], where the models are specified as modular structures with a wide range of

This paragraph of the first footnote will contain the date on which you submitted your paper for review. This work was supported by the European Commission through the European FP7 project iTesla under the grant agreement no283012.

Ö. Göksu, M. Altin, and P. Sørensen are with the Department of Wind Energy, Technical University of Denmark (DTU), Roskilde, 4000 Denmark (e-mail: omeg@dtu.dk, mfal@dtu.dk, posq@dtu.dk).

J. Fortmann is with the Hochschule für Technik und Wirtschaft (HTW) Berlin, Germany (e-mail: jens.fortmann@htw-berlin.de). parameters and the flexibility to cover a wide range of WT types and models, providing the opportunity to model manufacturer specific models in a generic and accurate way. The IEC standard [1] covers various types of WT models, and also WPP control models, which are developed as a frame of structures to be parametrized by the user (e.g. wind industry) of the model, such that the model can represent the real WT and WPP behavior in the most accurate way. In order to assure that the models can represent the behavior of the real wind generation units (WT and/or WPP) validation studies are needed, analyzing the accuracy of the models. The IEC standard [1] also introduces validation methodology for the wind generation models, based on measurements during voltage dips, reference point changes and grid protection (i.e. tripping of the WTs) cases. In the validation studies, the simulation of the model can be basically performed in two ways; namely as full grid simulation and play-back approach [1]. In the full grid simulation approach the grid is also modelled in addition to the wind generation unit, while in the play-back approach the recorded grid voltage is supplied and simulated as it is at the wind generation unit terminals. In this paper the full grid simulation approach is chosen, which means that an equivalent grid is modelled as well. Moreover, the same case is also simulated using the play-back approach and the results with the two approaches are compared against the measurements.

In this paper, the IEC type 3 (Doubly Fed Generator) WT model with the WPP controller are validated based on field measurements from a real 52 MW WPP, which is composed of 26 type 3 WTs of $2 \mathrm{MW}$ each and their WPP controller. The WPP under test is modeled using the IEC models; a fieldrecorded case is simulated; and simulation results are compared against the field measurements to show the accuracy of the models to represent the real WPP behavior.

In the following section existing validation studies are surveyed together with the validation methodologies. In the third section the IEC 61400-27-1 models are briefly introduced and the utilized control structure for the WT and WPP controller is shown. The WPP, grid modeling details and the validation results are given in the fourth section; the discussion of the results and further considerations are provided in the fifth section. In the last section concluding remarks are given. Parameters of the validated WT and WPP control models, based on the IEC 61400-27-1 standard, are provided in the appendix. 


\section{Wind Power Validation Studies State of the ART}

There have been extensive efforts on modeling and validation of wind generation models in the recent years, which include either field measurements or factory tests from real wind generation hardware, i.e. WTs and WPPs. The validation is generally configured in one of the two main approaches. In the first approach, a staged test is conducted such that a setpoint is sent to the WT/WPP or a controlled disturbance (e.g. fault) is created while measuring the response. In the other approach, measurement units are installed at the WT/WPP grid connection point(s) for longterm monitoring, and naturally occurred events (e.g. setpoint change, disturbance, tripping) are utilized for validation.

Validation of the vendor specific and also generic models has drawn great attention in the literature. In [4], a generic type 3 generator model has been proposed, which has been utilized by IEC [1] and Western Electricity Coordinating Council (WECC) [2] working groups, and validated against WT measurements during a voltage dip test. In [5]-[9], detailed however not generic type 3 WT models have been developed and validated against numerous tests and measurements from real WTs on the field; whereas in [10], the WECC type 3 model is validated against two vendors' WT measurement data. In [11], validation results for the WECC [2] and vendor specific models are given based on field or factory test measurements both at WT and WPP level. Moreover in [11], a WPP model validation is conducted based on staged tests of a 70 MW WPP with setpoint changes and disturbances, same as the cases in [12] and [13]. Similarly, a voltage control setpoint change and staged disturbances for WPPs are utilized to validate the manufacturer specific and power system software specific models in [14] and [15]. In [16]-[19], long-term recordings at the WPP connection points are utilized to validate EMT models during faults experienced by the WPPs, whereas the same has been performed for a type $3 \mathrm{WT}$ in [20]. While most of the staged field fault tests are performed for a single WT [4]-[10], a fault ride-through test has been conducted for a large (150 MW) WPP in [21], where a detailed WPP model is validated. The validation of IEC type 1A WT model has been performed in [22] based on field test measurements during a fault. Model of a real WPP based on the IEC type 3 WT and WPP controller, is being validated first time in this paper.

An important aspect of the validation of the wind generation models is to show that the model provides sufficient accuracy compared to the real response of the WT and WPP controller, which also implies accurate configuration and tuning of the model parameters. The parameters of the model can be deduced from the physical parameters of the WT and the controllers [4]. But since generic models are based on simplifications, tuning parameters against available measurements [12], [15], [23], - e.g. by using optimization like the heuristic optimization algorithm in [4] -, can provide improved accuracy. There are few methods and criteria that the accuracy of the model validation can be verified to comply with, such as [24] and [25]. In most of the validation studies, the model simulation results and the field measurements are observed to match the dynamic response in terms of rise time, settling time and oscillations, which play important role considering the impact on the power system [26].

As will be explained in the following parts, the measurement data for the validation in this paper is obtained by long-term monitoring of the WPP, recording fluctuations and a power factor change event; and selected parameters of the WPP model is tuned to match the model to the measurements from the WPP.

\section{IEC 61400-27-1 WIND GENERATION MODELS}

The IEC 61400-27-1 models are targeted to be used in fundamental frequency electromechanical (RMS) stability studies with a bandwidth of $15 \mathrm{~Hz}$, where the electromagnetic transient level dynamics are omitted in order to avoid modelling complexity and excess computation times especially for large scale power system analysis [1]. However, the models are still equipped with enough dynamics to be utilized for transient stability studies and especially with detailed control capabilities, e.g. fault ride-through. The focus of the modelling is to represent the dynamic grid response of the WT at the connection terminals, rather than the internal WT dynamics. The IEC models are specifically developed for

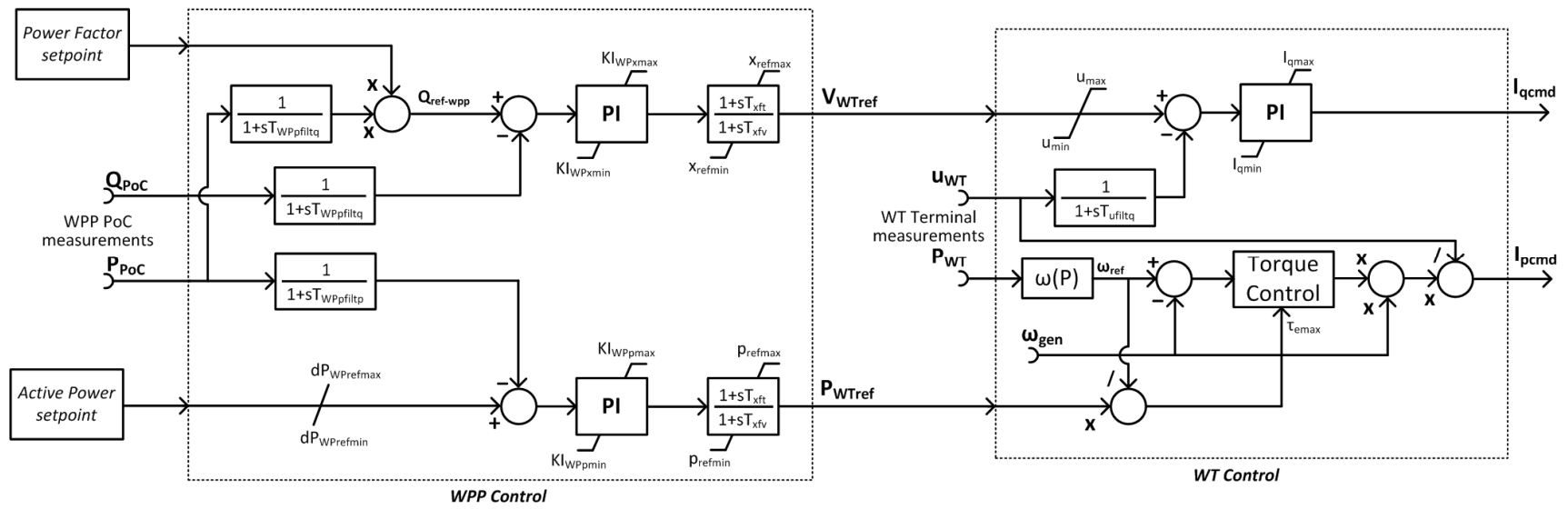

Fig. 1. Simplified block diagram for type 3 WT and WPP controller of IEC 61400-27-1. 
short-term stability studies; hence the wind speed is assumed to be constant during the dynamic cases and not used as an input. Instead, active power of the WT is limited with a reference input, which is received from the WPP control level. Hence, there is the possibility to use the active power limitation setpoint to create active power fluctuations, as performed in this paper. For the sake of space and clarity, only a simplified representation of the WT and WPP active and reactive power control structures from the IEC standard is shown in Fig. 1, with only emphasize to the loops operated by the WPP of this study; whereas the full models with details in [1] are implemented and simulated in this paper.

\section{A. Type 3 Wind Turbine Model}

The IEC standard type $3 \mathrm{WT}$ model [1] has five reactive power operating modes; namely voltage control, reactive power control, open loop reactive power control, power factor control, and open loop power factor control. In this study the type 3 WT under test is operated with the voltage control mode, as shown in Fig. 1. The voltage reference is received from the WPP controller and the voltage feedback is measured at the WT terminals, filtered and regulated with a proportional-integral (PI) controller. Here it should be noted that the integral gains of the PI controllers in this paper might be set as zero, which implies pure proportional type control. The type 3 WT model has a specific active power control loop based on a look-up table $(\omega(\mathrm{p}))$ to create generator speed reference based on the active power level and an inner torque controller, which acts on the rotor speed error and generates torque reference, whereas the active power limitation setpoint for the WT is utilized as the maximum value within the torque controller, as seen in Fig. 1.

\section{B. Wind Power Plant Control Model}

The IEC standard WPP controller [1] has four reactive power operating modes; namely voltage control, reactive power control, static voltage control, and power factor control. In this study the WPP under test is operated with the power factor control mode, as shown in Fig. 1. Based on the power factor setpoint and active power measurement at the Point of Connection (PoC), an internal reactive power reference, $\mathrm{Q}_{\text {ref- }}$ WPP, is created and regulated with a PI controller. The output of the reactive power PI regulator is the voltage reference to the WT controller. Similarly, the active power controller at the WPP level regulates the active power at the PoC with a PI controller. The IEC standard WPP controller is specified to control a WPP model, which is represented as a single aggregated WT model, but also a WPP layout comprising several WTs, as performed in this paper. In this case the same reference values, $\mathrm{V}_{\mathrm{WTref}}$ and $\mathrm{P}_{\mathrm{WTref}}$, are sent to all of the WTs in the WPP, in other words a special dispatching algorithm is not implemented. In the current edition of the IEC standard [1] and in this study no communication delay between the WPP controller and the WTs is considered. As seen in Fig. 1, both the active power and voltage references in the WPP controller are shaped by lead-lag blocks, which serve to represent the dynamics within a WPP.

\section{VALIDATION OF THE WIND TURBINE AND WIND POWER PLANT CONTROLLER MODELS}

In this section the IEC type 3 wind generation model and the WPP level power factor controller are validated against the field measurements from the WPP under test. The WPP will be introduced first with its electrical layout, and the validation details will be given afterwards. The validation will be performed first with the full grid simulation approach, and then the play-back approach.

\section{A. The WPP Layout and Grid Characteristics}

The WPP under test is an onshore 52 MW WPP, with 26 type $3 \mathrm{WTs}$ of $2 \mathrm{MW}$ each, connected to the transmission network in France. As shown in Fig. 2, a PMU is installed at the substation, where the WPP is connected. At the same substation a total of $20 \mathrm{MVAr}$ reactor units are also connected. The PoC, where the WPP controller acts for power factor control, is at the high voltage side of the WPP transformer.

For the full grid simulation approach a grid model is needed. In this study, the grid is represented with its Thevenin equivalent; the grid impedance is calculated from the available measurements as $0.024 \mathrm{pu}$ (at 100 MVA base), which implies a relatively strong grid, and the grid voltage is measured and set as $1.06 \mathrm{pu}$, as confirmed by the system operator of the grid.

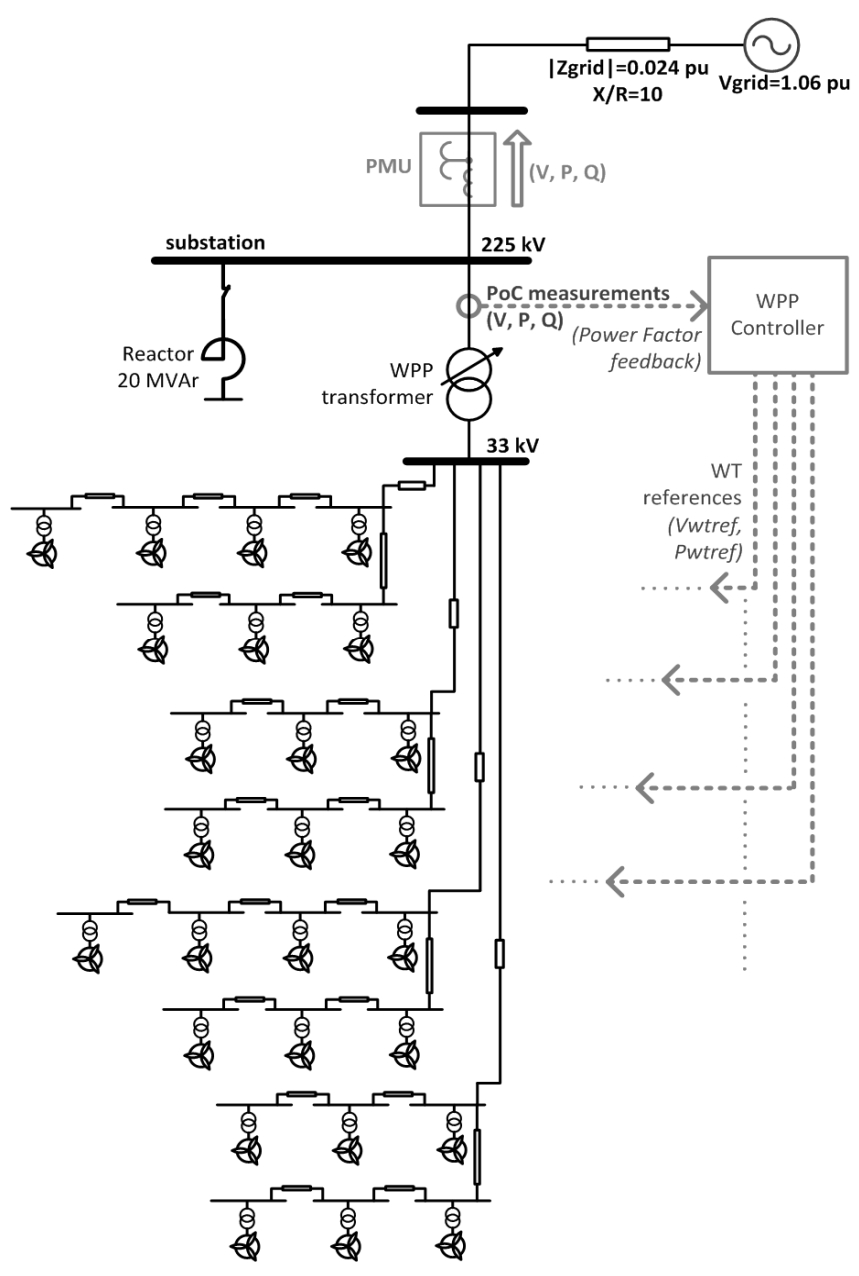

Fig. 2. The WPP layout, grid, and PMU location [Sbase=100 MVA]. 
The WPP model in Fig. 2 is modeled in DIgSILENT PowerFactory as RMS simulation model. As mentioned in the introduction, the long-term monitoring approach is utilized and data is collected by the PMU. The most critical control parameters of the WPP simulation model are tuned to match the real WPP behavior utilizing the fluctuating active and reactive power measurement data. In this case, the PI gains of the WPP active and reactive power controllers $\left(\mathrm{K}_{\mathrm{PWP}}, \mathrm{K}_{\mathrm{IWP}}\right.$, $\mathrm{K}_{\text {PWPX }}, \mathrm{K}_{\text {IWPX }}$ ) are selected and manually tuned, which gave satisfactory accuracy between the simulated model and measured behavior, as will be seen in the following parts. However, it should be noted that utilizing the real settings, if available, from the WTs and WPP controller would be more effective for tuning, together with additional manual and/or automatic adjustments. Moreover, the tuned models would better be further validated against other type of event(s), as validation of the tuning, which would increase confidence of the model. In this study no parameter identification approach is utilized, whereas it could be inevitably necessary in case of a validation for a fault case, for instance in [4]. It is worth to mention that the recorded PMU data is checked to be consistent with the regional recordings at the grid operator's control center. All values for the active and reactive power control parameters of the models, which are used and validated for the WPP and the WT, are given in the appendix. It should be noted that the shown behavior of the WPP cannot be considered as grid connection compliance or performance evaluation of the WPP.

\section{B. Comparison of Simulation Results and Field Measurements for WPP Power Factor Change}

In this section measured data during a power factor change event is utilized for validation, whereas the long-term behavior before and after the transient event is shown and used for validation as well. In Fig. 3 to 6, the long-term behavior (22.5 minutes before and 22.5 minutes after the power factor change) is shown, whereas the detailed transient behavior during WPP's power factor change is shown in Fig. 7 to 9.

As mentioned above, the IEC WPP control model has the input for the active power limitation; and in this paper the measured active power is supplied as active power limitation setpoint to the WPP controller, similar to the approach used in [4] and proposed in [12]. Thus the active power fluctuations during the whole period could be simulated (Fig. 4), which also helps to verify the long-term power factor control by the WPP controller (Fig. 5). However, as explained in the third section, the IEC standard has been developed for short-term dynamic studies assuming constant wind speed, whereas the active power setpoint is used as a limitation reference. Hence the approach above is utilized only to stimulate the long-term active power fluctuations in an artificial way and do not specifically validate the active power control loop. As explained in the second section (Fig. 1), the WPP generates an (internal) reactive power reference based on the active power level and the power factor setpoint, and regulates the reactive power by modifying the voltage reference for the turbines.

In Fig. 3, the reactive power measured by the PMU at the substation is shown, together with the corresponding simulation results, where the WPP power factor change takes



Fig. 3. Measured (solid gray) and simulated (dashed black) reactive power (45 minutes period).

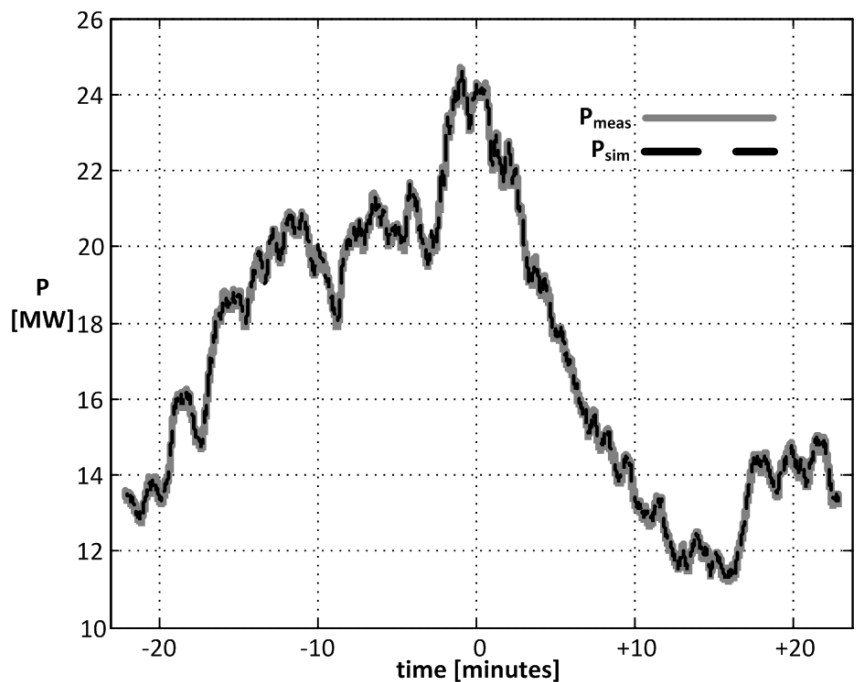

Fig. 4. Measured (solid gray) and simulated (dashed black) active power (45 minutes period).

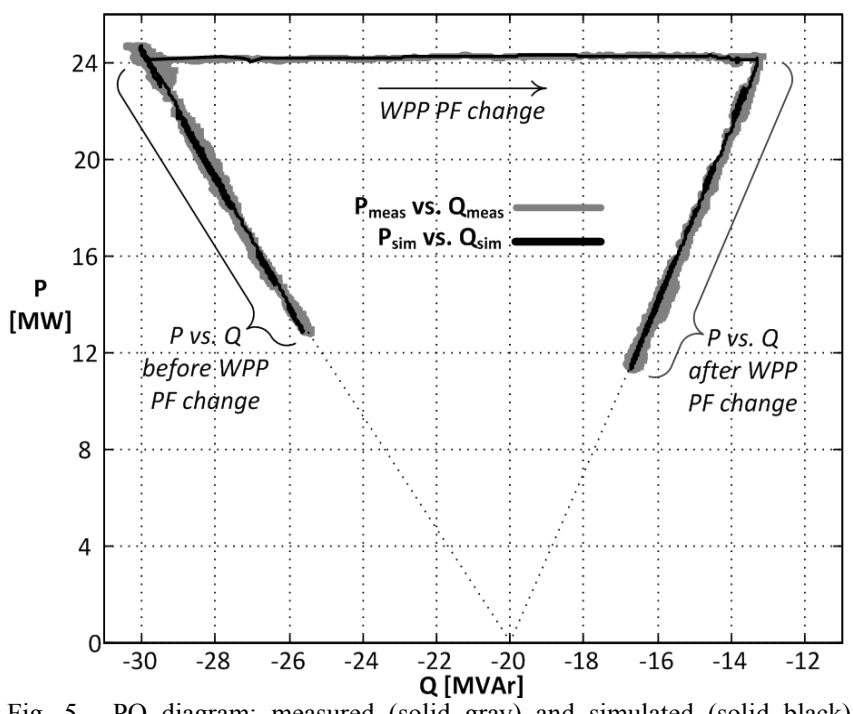

Fig. 5. PQ diagram; measured (solid gray) and simulated (solid black), 22.5 minutes periods before and after the WPP power factor (PF) change. 
place at the instant the time equal to zero. The effect of the 20 MVAr reactors at the substation is seen as an offset of -20 MVAr in Fig. 3, where the reactive power steps from -29 MVAr to -13 MVAr as the WPP changes its power factor. As seen in Fig. 4, at the instant of the WPP power factor change, the active power measurement at the substation is around 24 MW, which is the power level of the WPP. First, the WPP operates with 0.94 leading (i.e. underexcited) power factor, such that it absorbs around 9 MVAr at $24 \mathrm{MW}$ power level just before the power factor change (resulting in -29 MVAr in Fig. 3); and WPP's power factor changes to 0.96 lagging (i.e. overexcited), such that it injects 7 MVAr just after the change (resulting in -13 MVAr in Fig. 3).

In Fig. 5, PQ behavior at the substation is drawn both for the measurements and simulations for the whole period of 45 minutes, including the periods before and after the WPP power factor change event. As observed in Fig. 5, the WPP's active power fluctuates between $11 \mathrm{MW}$ and $25 \mathrm{MW}$ during the period, and the reactive power steps from -29 MVAr to -13 MVAr at the substation, when the WPP's power factor changes at a level of $24 \mathrm{MW}$. Since the full grid simulation approach is utilized in this section, it is possible to compare the resultant simulation voltage at the substation bus against the measured voltage, as given in Fig. 6. Considering that the total absorbed reactive power from the grid decreases by 16 $\operatorname{MVAr}(0.16 \mathrm{pu}$ at $100 \mathrm{MVA}$ base) and the grid impedance is $0.024 \mathrm{pu}$, the voltage step rise at the power factor change instant is around $0.0038 \mathrm{pu}$, as expected. The voltage deviation after the $15^{\text {th }}$ minute is explained to be due to grid voltage fluctuations/sags occurring external to the WPP.

In Fig. 7, the reactive power transient at the substation bus is shown in detail during the WPP power factor change event, where a very small deviation is observed between the measured and the simulated response at 30 seconds before the transient event, which will be explained with voltage (Fig. 9). As seen in Fig. 7, at the first instant of the step change the simulation follows the measurement with a small delay and slightly steeper increase, which is considered to be eliminated if the real settings from the WTs and WPP controller were utilized while tuning the model. In Fig. 8, measured and simulated active power are compared. Owing to the tuned bandwidth (including the ramp rate limiters on the reference

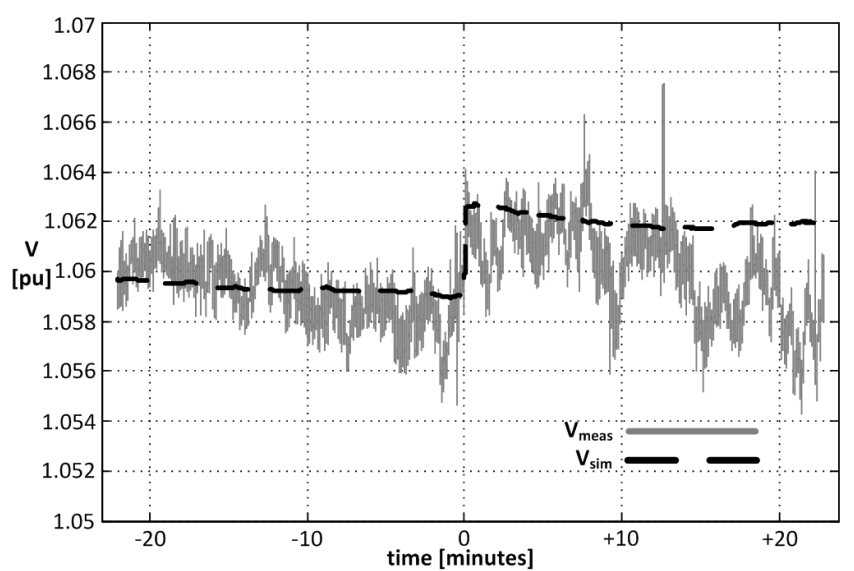

Fig. 6. Measured (solid gray) and simulated (dashed black) substation voltage (45 minutes period).

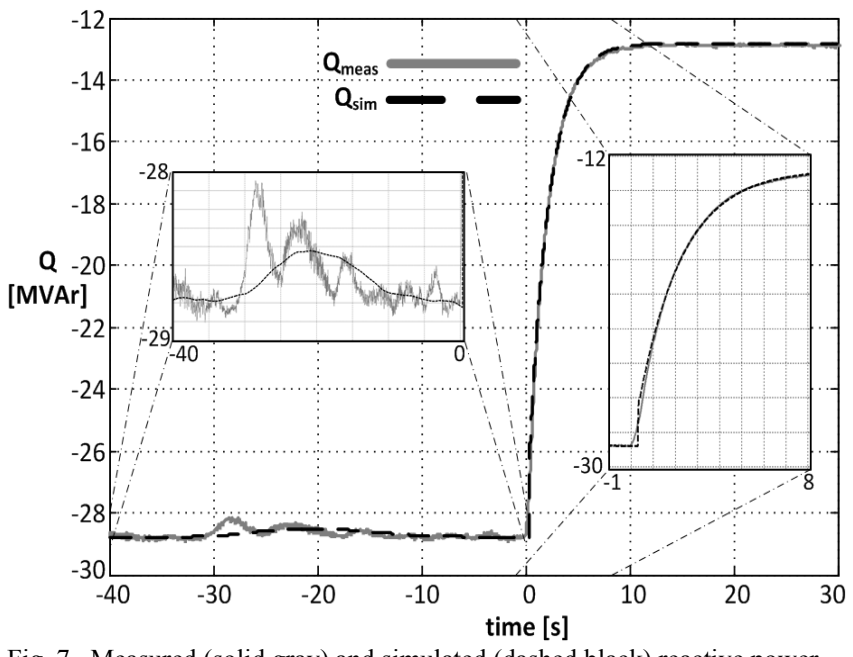

Fig. 7. Measured (solid gray) and simulated (dashed black) reactive power during WPP power factor change.

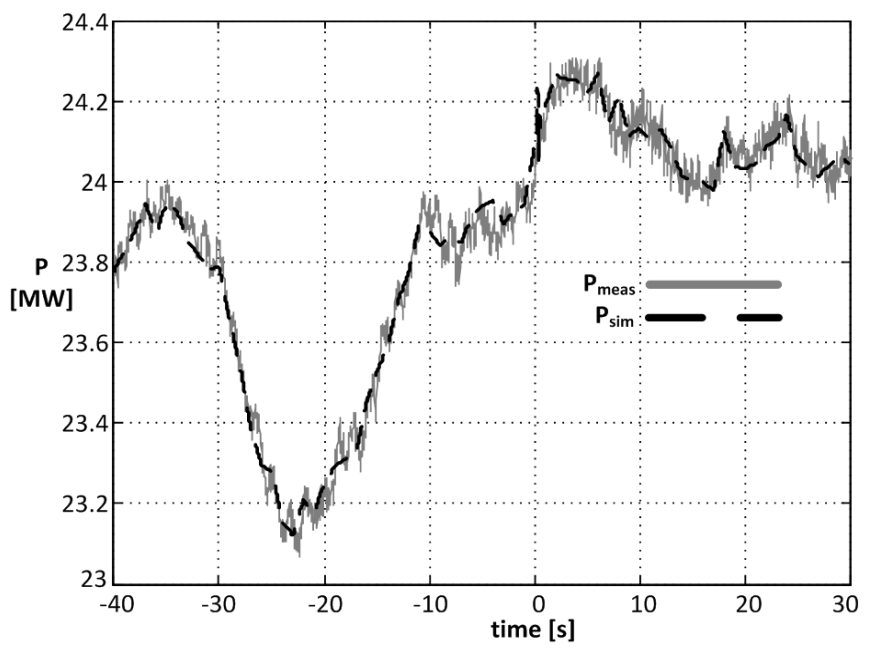

Fig. 8. Measured (solid gray) and simulated (dashed black) active power during power factor change.

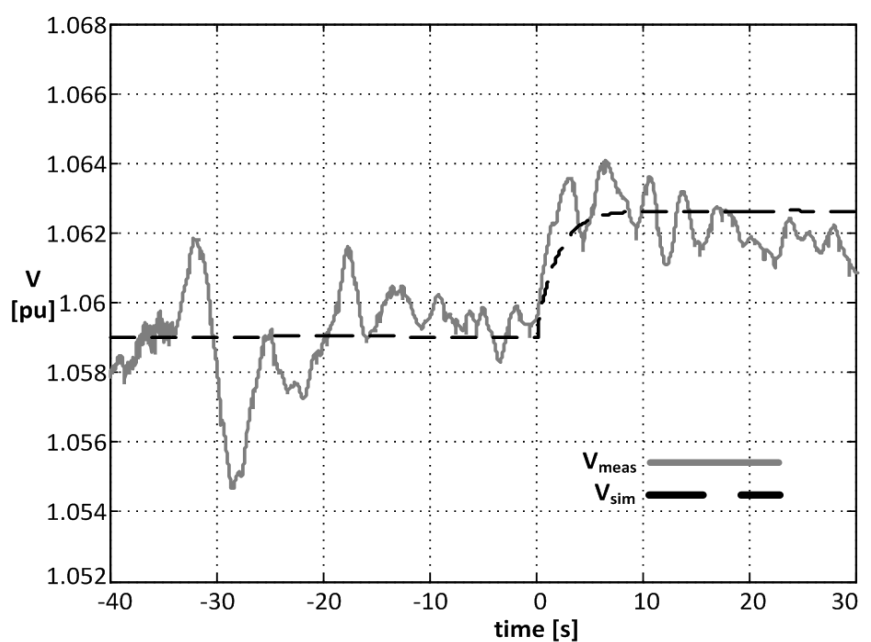

Fig. 9. Measured (solid gray) and simulated (dashed black) substation voltage during power factor change.

path and low-pass filters on the feedback path) of the WPP active power controller, the higher frequency but low magnitude oscillations (approximately $10 \mathrm{~Hz}$ ) at the measured response are not observed in the simulated response, which is 
acceptable for fundamental frequency power system stability studies. Nevertheless, it is always possible to tune the WPP controller for faster response, if required.

In Fig. 9, the substation voltage transient during the WPP's power factor change is shown. The simulated voltage response is able to match the steady state behavior and the step rise during the WPP's power factor change; however the oscillations (approximately $0.3 \mathrm{~Hz}$ ) in the voltage cannot be captured by the simulation model, since the grid is modeled by its Thevenin equivalent, without any power system control dynamics or conventional power plants or loads. The small deviation between the measured and simulated reactive power oscillations in Fig. 7 can be explained to be due to this mismatch between the measured and simulated voltages in Fig. 9. In order to see the impact of the grid voltage oscillations on the reactive power response, mostly due to the reactors at the substation, the same transient case is simulated using the play-back approach in the next section.

\section{Comparison of Play-Back and Full Grid Simulation Results with the Field Measurements}

In this section the same power factor change event is simulated using the play-back approach, such that the recorded voltage-time series at the substation bus is applied at the corresponding substation bus in the simulations, where the grid model is not utilized anymore. Similar to the case in the previous section, the measured active power is fed as the active power limitation reference for the WPP and the resultant reactive power response is compared against the measured, in Fig. 10 below. As can be seen especially in the zoomed period of Fig. 10, the measured and simulated reactive power are matching, such that the oscillations in the reactive power due to the voltage oscillations (Fig. 9) could be captured.

In Fig. 11, the reactive power of measurement, the full grid simulation, and the play-back simulation are compared for the period before the power factor change event. As seen, the full grid simulation approach with the Thevenin equivalent grid is able to capture only the non-oscillatory behavior, while the play-back approach can capture the impact of the oscillatory grid voltage.

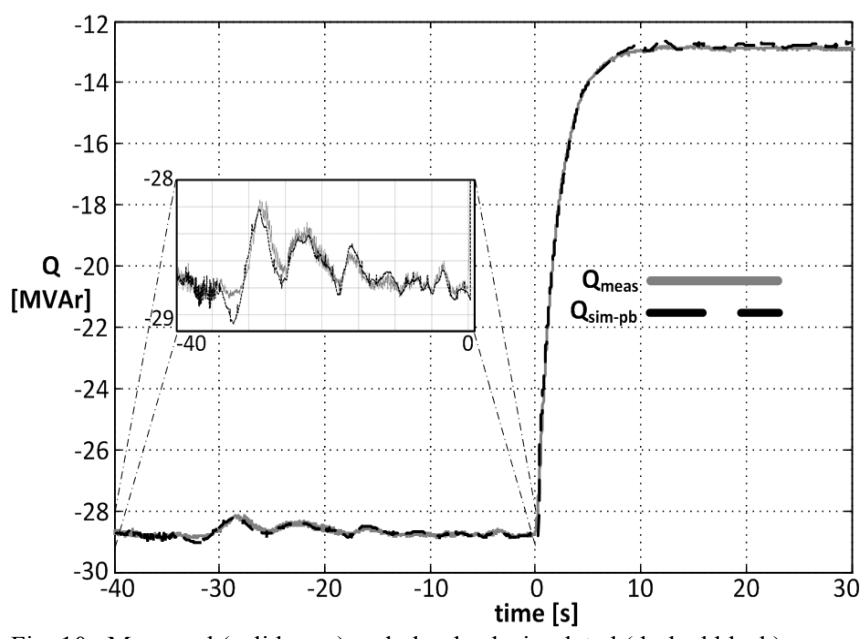

Fig. 10. Measured (solid gray) and play-back simulated (dashed black) reactive power during WPP power factor change.

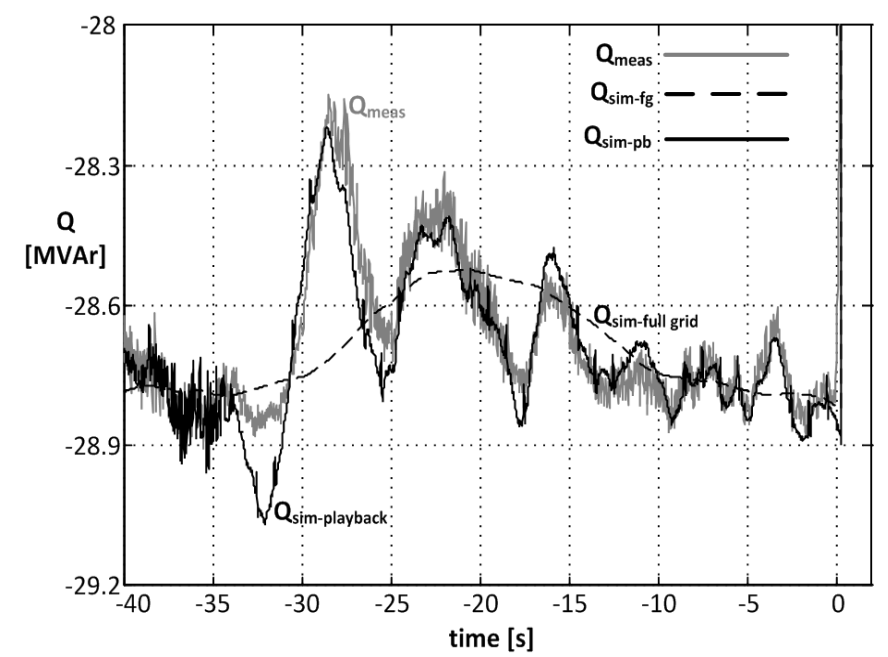

Fig. 11. Measured (solid gray), full grid simulated (dashed black), and playback simulated (solid black) reactive power before WPP power factor change.

\section{DisCUSSION OF RESUlts AND RECOMMENDATIONS}

As seen in the previous section via the comparison between the field measurements of a real WPP and its simulation model with the IEC 61400-27-1 wind generation models, the validated model can adequately represent the WPP behavior during steady state (power factor control against active power fluctuations) and a transient power factor change event.

The only considerable discrepancy has been observed for the grid voltage oscillations, which is explained to be due to the simplified representation of the grid in the full-grid simulation approach. This can be improved via modeling the grid with more details, which can be obtained from the grid operator. The impact of these oscillations could also be analyzed via performing the same validation case with the play-back approach. Although the play-back approach is found to perform better to capture the real response of the WPP including the impact of the grid on the WPP, the full grid simulation approach always gives opportunity to see the impact of the WPP on the power system, which is essentially required for power system stability analysis, provided that the grid is modelled with enough details.

It is shown in this paper that the WPP active power fluctuations, which originate from wind speed fluctuations, can be incorporated into the IEC wind generation models via feeding the measured active power as the WPP active power limitation reference signal. However, it should be kept in mind that this approach might create a discrepancy between the measured and simulated internal WT dynamics, such as the pitch angle, which is not under concern in this study. Although the IEC models are aimed for short-term (10 to 30 seconds) of simulation, in this study the use of the IEC models is extended for long-term simulations, which gives the possibility to compare power factor control response against fluctuating active power. In the validation case of this paper, a power factor change event from 0.94 leading to 0.96 lagging is used while the WPP was producing $24 \mathrm{MW}$ (46\% of rated) active power. It should be noted that during higher power production levels such power factor setpoints might exceed the reactive power capability limits of the type $3 \mathrm{WTs}$, which are typically designed for power factor of $+/-0.95$ at rated power. 
Nevertheless, the IEC WT models incorporate voltage and active power dependent Q limitation lookup tables [1], where the physical PQ diagram of WTs can be implemented in the simulations.

In this paper the field measurements are obtained by installing a PMU unit at the substation, where the WPP is connected together with the reactors at the same substation. The validation could be further detailed if the WPP measurements were available at the PoC; and improved via recording and utilizing the internal response within the WPP, such as the references from the WPP controller to each of the WTs. In case of a validation study that includes tripping of some of the WTs in the WPP (e.g. due to a frequency event), status data from the WPP and all the WTs could be valuable to perform a detailed and precise validation study, as mentioned in [16]. Additionally, recording behavior of other units (e.g. switched reactors, statcom) would provide increased accuracy for the modeling and validation. In the current edition of the IEC wind generation models [1], no communication delay between the WPP controller and the WTs, and no measurement (power, voltage feedback) delay is taken into account. The impact of these delays could be significant in case a controlled test is performed, such as a fault ride-through of a WPP, which stands as a future work. It should be noted that the communication and measurement delays, as well as the auxiliary units (e.g. statcom) are being considered to be included in the future edition of the IEC 61400-27, where more detailed WPP control models are going to be described.

\section{CONCLUSION}

In this paper a transmission level $52 \mathrm{MW}$ WPP with 26 of type $3 \mathrm{WTs}$ in voltage control mode with plant level power factor controller is modelled using the IEC 61400-27-1 wind generation WT and WPP controller models. The model is simulated and validated against the field measurements from the grid connection point of this WPP, for steady state WPP level power factor control against active power fluctuations and a transient power factor change event. It is shown that the IEC models are able to reproduce the WPP behavior to be used in power system stability studies, especially in large-area analysis. The reactive power control capability of the WPP could be modeled and validated using the IEC models, which is important for short-term and long-term voltage stability studies. The two validation approaches, the full grid simulation and the play-back, are utilized and compared for the same event for the first time in this paper.

The IEC type 3 WT model in voltage control and WPP reactive power controller in power factor control mode are validated first time at WPP level, and it is shown that an operating point change or response to a disturbance can be effectively used for validation studies at this level.

Further considerations for the future validation studies and IEC models are provided, such that the necessities for additional recordings within the WPP data flow and status of all single units (e.g. WTs, reactors) are emphasized. Validation of the IEC models at WT and WPP level with different control configurations (e.g. voltage control at WPP level) and also during a low voltage fault close to the WPP connection point or frequency drop event stand as a future work.

\section{ACKNOWLEDGEMENT}

Support of Jean-Baptiste Heyberger from RTE is highly appreciated and acknowledged.

\section{APPENDIX}

In the table below, all the values for the validated IEC WT and WPP active and reactive power controller models of this paper are given based on the IEC standard [1]. However, it should be noted that, neither the control structures (Fig. 1) in this paper nor the parameter values can be considered to reflect the physical control structure of the WPP under test, which might have a different control structure and tuning. For the sake of space, only the parameter names and their values are given in the tables below, whereas corresponding descriptions and base units can be found in [1]. In this validation study only the selected critical parameters related to the WPP power factor control are tuned and validated against field measurements. Other parameters, such as gains related to fault ride-through, need to be identified and validated separately. Additionally, most of the hardware related parameters, such as the active and reactive power and current capability limits, are always better set by the WT manufacturer.

TABLE I

PARAMETER VALUES OF WT AND WPP CONTROLLER [1]

\begin{tabular}{|c|c|c|c|c|c|c|c|}
\hline \multicolumn{4}{|c|}{ WT Control Parameters } & \multicolumn{4}{|c|}{ WPP Control Parameters } \\
\hline \multicolumn{2}{|c|}{ P Control } & \multicolumn{2}{|c|}{ Q Control } & \multicolumn{2}{|l|}{ P Control } & \multicolumn{2}{|c|}{ Q Control } \\
\hline$\omega_{\text {offset }}$ & 0.02 & $M_{q G}$ & 0 & $T_{W P p f i l t p}$ & 0.02 & $x_{\text {refmax }}$ & 0.5 \\
\hline$K_{P p}$ & 8 & $M_{q U V R T}$ & 2 & $T_{\text {WPffiltp }}$ & 0.02 & $x_{\text {refmin }}$ & -0.5 \\
\hline$K_{I p}$ & 5 & $T_{\text {ufiltq }}$ & 0.005 & $d p_{\text {WPrefmax }}$ & 1 & $T_{x f t}$ & 0.01 \\
\hline$T_{p f i l t p 3}$ & 0.005 & $T_{\text {pfiltq }}$ & 0.005 & $d p_{\text {WPrefmin }}$ & -1 & $T_{x f v}$ & 0.02 \\
\hline$T_{\text {ufiltp } 3}$ & 0.005 & $K_{P q}$ & 5 & $K_{\text {WPpref }}$ & 1 & $K_{P W P x}$ & 0.08 \\
\hline$T_{\text {wref }}$ & 5 & $K_{I q}$ & 0 & $K_{P W P p}$ & 0.1 & $K_{I W P x}$ & 0.345 \\
\hline$T_{\omega f i l t p 3}$ & 0.05 & $K_{P u}$ & 2 & $K_{I W P p}$ & 1 & $K_{W P q u}$ & 0 \\
\hline$K_{D T D}$ & 1.5 & $K_{I u}$ & 0 & $T_{p f t}$ & 0.01 & $T_{\text {WPufiltq }}$ & 0.02 \\
\hline$p_{D T D \max }$ & 0.15 & $u_{d b 1}$ & 0 & $T_{p f v}$ & 0.02 & $T_{\text {WPqfiltq }}$ & 0.02 \\
\hline$\zeta$ & 0.5 & $u_{d b 2}$ & 2 & $d p_{\text {refmax }}$ & 1 & $T_{\text {WPpfiltq }}$ & 0.02 \\
\hline${ }^{\omega} D T D$ & 11.3 & $K_{q v}$ & 2 & $d p_{\text {refmin }}$ & -1 & $T_{\text {uqfilt }}$ & 0.02 \\
\hline$T_{\text {pord }}$ & 0.01 & $u_{\max }$ & 1.15 & $p_{\text {refmax }}$ & 1.1 & $u_{W P q d i p}$ & 0.9 \\
\hline$d p_{\max }$ & 0.3 & $u_{\min }$ & 0.85 & $p_{\text {refmin }}$ & 0 & $K_{\text {WPqref }}$ & 0 \\
\hline$d p_{\text {refmax }}$ & 999 & $u_{\text {refo }}$ & 0 & $K_{\text {IWPpmax }}$ & 1.1 & $K_{I W P x \max }$ & 0.5 \\
\hline$d p_{\text {refmin }}$ & -0.3 & $u_{q d i p}$ & 0.9 & $K_{I W P p m i n}$ & 0 & $K_{I W P x \min }$ & -0.5 \\
\hline$u_{p d i p}$ & 0.9 & $T_{\text {qord }}$ & 0 & & & $d x_{\text {refmax }}$ & 99 \\
\hline$d \tau_{\max }$ & 0.25 & $T_{\text {post }}$ & 0 & & & $d x_{\text {refmin }}$ & -99 \\
\hline$\tau_{\text {emin }}$ & 0.001 & $i_{\text {qmax }}$ & 1.05 & & & $M_{\text {WPqmode }}$ & 1 \\
\hline$\tau_{\text {uscale }}$ & 1 & $i_{\text {qmin }}$ & -1.05 & 49.2 & 0 & -0.2 & -0.1 \\
\hline$M_{p U V R T}$ & 1 & $i_{q h 1}$ & 1.05 & 49.8 & 0 & -0.05 & -0.02 \\
\hline$d \tau_{\max U V R T}$ & 0 & $i_{\text {qpost }}$ & 0 & $p_{\text {WPbias }} 50$ & 0 & $q_{\mathrm{WP}}$ & 0 \\
\hline$u_{D V S}$ & 0.15 & $r_{\text {droop }}$ & 0 & 50.2 & 0 & 0.05 & 0.02 \\
\hline$T_{D V S}$ & 0.05 & $x_{\text {droop }}$ & 0 & 50.8 & 0 & 0.2 & 0.1 \\
\hline 0 & 0.76 & & & & & & \\
\hline 0.3 & 0.76 & & & & & & \\
\hline 0.31 & 0.86 & & & & & & \\
\hline 0.4 & 0.94 & & & & & & \\
\hline 0.5 & 1 & & & & & & \\
\hline 1 & 1 & & & & & & \\
\hline
\end{tabular}




\section{REFERENCES}

[1] Wind Turbines-Part 27-1: Electrical Simulation Models - Wind Turbines, IEC Standard 61400-27-1 ed. 1, Feb. 2015.

[2] E. Muljadi and A. Ellis, "Final project report WECC wind generator development," presented at the California Inst. Energy Environ., Mar. 2010.

[3] CIGRE Technical Brochure 328, "Modeling and Dynamic Behavior of Wind Generation as it Relates to Power System Control and Dynamic Performance," CIGRE WG C4.601, Aug. 2007.

[4] J. Fortmann, S. Engelhardt, J. Kretschmann, C. Feltes, and I. Erlich, "New Generic Model of DFG-Based Wind Turbines for RMS-Type Simulation," IEEE Trans. Energy Conversion, vol.29, no.1, pp. 110-118, March 2014.

[5] L. Trilla, O. Gomis-Bellmunt, A. Junyent-Ferre, M. Mata, J. Sanchez Navarro, and A. Sudria-Andreu, "Modeling and Validation of DFIG 3MW Wind Turbine Using Field Test Data of Balanced and Unbalanced Voltage Sags," IEEE Trans. Sustainable Energy, vol. 2, no. 4, pp. 509519, Oct. 2011.

[6] F. Jiménez, E. Gómez-Lázaro, J. A. Fuentes, A. Molina-García, and A Vigueras-Rodríguez, "Validation of a DFIG wind turbine model submitted to two-phase voltage dips following the Spanish grid code," Renewable Energy, vol. 57, pp. 27-34, Sept. 2013.

[7] F. Jiménez, E. Gómez-Lázaro, J. A. Fuentes, A. Molina-García, and A. Vigueras-Rodríguez, "Validation of a double fed induction generator wind turbine model and wind farm verification following the Spanish grid code," Wind Energy, vol. 15, no. 4, pp. 645-659, 2012.

[8] S. Seman, J. Niiranen, R. Virtanen, and J.-P. Matsinen, "Low voltage ride-through analysis of 2 MW DFIG wind turbine - grid code compliance validations," in Proc. IEEE Power and Energy Society General Meeting, July 2008.

[9] A. Petersson, T. Thiringer, L. Harnefors, and T. Petru, "Modeling and experimental verification of grid interaction of a DFIG wind turbine," IEEE Trans. Energy Conversion, vol. 20, no.4, pp. 878-886, Dec. 2005.

[10] WECC Type 3 Wind Turbine Generator Model - Phase II (January 23, 2014) [Online] Available: https://www.wecc.biz/Reliability/WECCType-3-Wind-Turbine-Generator-Model-Phase-II-012314.pdf

[11] M. Asmine, J. Brochu, J. Fortmann, R. Gagnon, Y. Kazachkov, C.-E. Langlois, C. Larose, E. Muljadi, J. MacDowell, P. Pourbeik, S. A. Seman, and K. Wiens, "Model Validation for Wind Turbine Generator Models," IEEE Trans. Power Systems, vol. 26, no. 3, pp.1769-1782, Aug. 2011.

[12] M. P. Richwine, J. J. Sanchez-Gasca, and N. W. Miller, "Validation of a second generation Type 3 generic wind model," in Proc. IEEE Power and Energy Society General Meeting, July 2014.

[13] J. M. MacDowell, K. Clark, N. W. Miller, and J. J. Sanchez-Gasca, "Validation of GE wind plant models for system planning simulations," in Proc. IEEE Power and Energy Society General Meeting, July 2011.

[14] M. Fischer, A. Mendonca, and P. Godin, "Voltage Control with Wind Farms: Current Practice with Type 4 WTG in Canada," in Proc. IEEE Electrical Power and Energy Conference, pp. 165-169, Nov. 2014.

[15] S. Auddy, R. K. Varma, and M. Dang, "Field Validation of a Doubly Fed Induction Generator (DFIG) Model," in Proc. IEEE Electrical Power Conference, pp. 484-489, Oct. 2007.

[16] Y. Zhang, E. Muljadi, D. Kosterev, and M. Singh, "Wind Power Plant Model Validation Using Synchrophasor Measurements at the Point of Interconnection," IEEE Trans. Sustainable Energy, vol. 6, no. 3, pp. 984-992, July 2015.

[17] M. Singh, K. Faria, S. Santoso, and E. Muljadi, "Validation and analysis of wind power plant models using short-circuit field measurement data," in Proc. IEEE Power and Energy Society General Meeting, July 2009.

[18] M. Chaudhary, S. M. Brahma, and S. J. Ranade, "Validated short circuit modeling of Type 3 Wind Turbine Generator with crowbar protection," in Proc. North American Power Symposium, Sept. 2013.

[19] S. Zhao and N.-K.C. Nair, "Assessment of wind farm models from a transmission system operator perspective using field measurements," IET Renewable Power Generation, vol. 5, no. 6, pp. 455-464, Nov. 2011.

[20] M. Bongiorno and T. Thiringer, "A Generic DFIG Model for Voltage Dip Ride-Through Analysis," IEEE Trans. Energy Conversion, vol. 28, no. 1, pp. 76-85, March 2013.

[21] B. Badrzadeh and A. Halley, "Challenges Associated With Assessment and Testing of Fault Ride-Through Compliance of Variable Power Generation in Australian National Electricity Market," IEEE Trans. Sustainable Energy, vol. 6, no. 3, pp. 1160-1168, July 2015.
[22] H. Zhao, Q. Wu, I. Margaris, J. Bech, P. E. Sørensen, and B Andresen, "Implementation and validation of IEC generic type 1A wind turbine generator model," Int. Trans. on Electr. Energ. Syst., vol. 25 , no. 9. pp. 1804-1813, 2014

[23] A. Honrubia-Escribano, E. Gomez-Lazaro, A. Vigueras-Rodriguez, A. Molina-Garcia, J. A. Fuentes, and E. Muljadi, "Assessment of DFIG simplified model parameters using field test data," in Proc. IEEE Power Electronics and Machines in Wind Applications, July 2012.

[24] The Australian Energy Market Operator (AEMO) (2008). Generating System Model Guidelines [Online]. Available: http://www.aemo.com.au /About-the-Industry/Registration/How-to-Register/Generating-SystemModel-Guidelines-and-Datasheets

[25] Asociación Empresarial Eólica (AEE) (2011). Procedure for Verification Validation and Certification of the Requirements of the PO 12.3 on the Response of Wind Farms and Photovoltaic Plants in the Event of Voltage Dips [Online]. Available: http://www.aeeolica.org/uploads /documents/1306-pvvc-n9-english.pdf

[26] M. Y. Borodulin, "Validation of wind turbine generator stability models for wind generation interconnection studies," in Proc. IEEE Power and Energy Society General Meeting, July 2014.

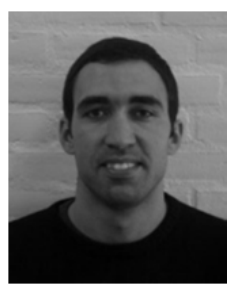

Ömer Göksu (S'07-M'13) received B.Sc. and M.Sc degrees in electrical and electronics engineering from METU, Ankara, Turkey in 2004 and 2008, and was employed in Aselsan Inc. from 2004 to 2009. He obtained his $\mathrm{PhD}$ degree from the Department of Energy Technology, Aalborg University, Denmark, in 2012, under the Vestas Power Programme. In 2013, he was a research associate at the University of Manchester, UK. Currently, he is with the DTU Wind Energy. His research area includes wind power control and modeling, integration of power electronics to power systems, and electrical motor drives.

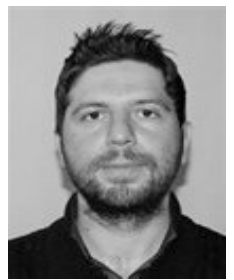

Müfit Altin (S'09-M'13) received B.Sc. and M.Sc. degrees in electrical and electronics engineering from the Middle East Technical University (METU), Ankara in 2004 and 2008, respectively. He obtained his PhD degree from the Department of Energy Technology, Aalborg University, Denmark, in 2012, where he was employed as a researcher under the Vestas Power Programme during his PhD. Since February 2013, he has been as a postdoc researcher at the Department of Wind Energy of the Technical University of Denmark. His research interest includes grid connection of wind power, wind power plant control, power system modelling, and power system stability analysis.

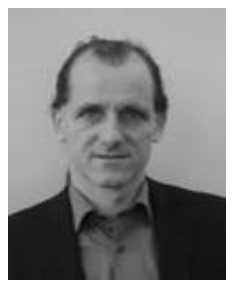

Jens Fortmann (M’05) received his Dipl.-Ing. degree in electrical engineering from the Technical University Berlin, Germany, in 1996 and his $\mathrm{PhD}$ from the University of Duisburg-Essen in 2013. From 1995 to 2015 he worked on the modelling, control design and grid integration of variable speed wind turbines at different wind turbine manufacturers. Since 2015 he is Professor for Wind Energy and Grid Integration at the HTW Berlin - University of Applied Sciences, Germany. His research interest includes control, modeling and grid integration of renewable sources. He is the head of the FGW working group that specifies the modeling and model validation guideline TR4

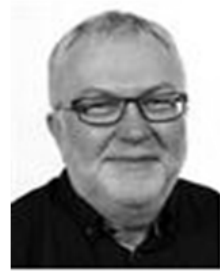

Poul Sørensen (M'04-SM'07) was born in 1958. He received the M.Sc. degree in electrical engineering from the Technical University of Denmark, Copenhagen, Denmark, in 1987. Since 1987, he has been at Risø National Laboratory, Roskilde, where he is currently a Professor. His research interests include integration of wind power into power systems, involving a variety of technical disciplines including power system control and stability, dynamic modeling and control of wind turbines and wind farms, and wind fluctuation statistics. Prof. Sørensen is convener of the IEC 61400-27 working group. 